Research Article

\title{
Plaque Index, Oral Hygiene Habits, and Depressive Symptomatology as Predictors of Clinical Attachment Loss: A Pilot Study
}

\author{
Norma Idalia Rodríguez Franco ${ }^{1}$ and José Moral de la Rubia $\mathbb{i}^{2}$ \\ ${ }^{1}$ Universidad Autónoma de Nuevo León, Facultad de Odontología, Monterrey, NL ZIP 64460, Mexico \\ ${ }^{2}$ Universidad Autónoma de Nuevo León, Facultad de Psicología, Monterrey, NL ZIP 64460, Mexico \\ Correspondence should be addressed to José Moral de la Rubia; jose_moral@hotmail.com
}

Received 29 February 2020; Revised 13 June 2020; Accepted 24 June 2020; Published 14 July 2020

Academic Editor: Li Wu Zheng

Copyright (C) 2020 Norma Idalia Rodríguez Franco and José Moral de la Rubia. This is an open access article distributed under the Creative Commons Attribution License, which permits unrestricted use, distribution, and reproduction in any medium, provided the original work is properly cited.

Background. The effect of depressive symptomatology on periodontitis is not clear in its path of action. Objective. To test a model to predict clinical attachment loss by direct effect of the dental plaque accumulation, which is a direct effect of worse oral hygiene habits and an indirect effect of greater depressive symptomatology. Methods. Three incidental samples were collected: 35 dental patients with periodontitis, 26 mental health patients with depressive symptomatology, and 29 people from the general population. The Beck Depression Inventory-II and the Oral Hygiene Habits Scale were applied. Plaque index and clinical attachment loss were assessed. Path analysis was used to test the model. The parameters were estimated by the maximum-likelihood method. Results. Depressive symptomatology had no direct effect on oral hygiene habits nor an indirect effect (mediated by oral hygiene habits) on the plaque index in any of the 3 samples. Oral hygiene habits had a large-size direct effect on plaque index and a medium-size indirect effect on clinical attachment loss in the general population sample. The plaque index had a direct effect on clinical attachment loss with a large effect size in general population sample and with a medium effect size in dental patients and depressive symptomatology patients. Conclusion. The model shows that dental plaque accumulation has a direct effect on clinical attachment loss in the 3 samples, and oral hygiene habits have an indirect effect on attachment loss mediated by dental plaque accumulation only in the general population sample. However, depressive symptomatology is not a relevant variable.

\section{Introduction}

Periodontitis is an infectious disease that results in inflammation of the supporting tissues of the teeth, clinical attachment loss (CAL), and bone loss. It is associated with the presence of dental plaque and calculus [1]. The clinical characteristics that identify periodontitis are as follows: interproximal CAL $\geq 2$ or $3 \mathrm{~mm}$, interdental CAL detectable at 2 or more nonadjacent teeth, and presence of interproximal tissue loss confirmed through radiographic assessments [2], as well as bleeding at probing, periodontal

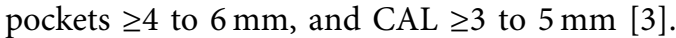

The severity of periodontitis is classified according to CAL and three stages are defined: stage I with a CAL from 1 to $2 \mathrm{~mm}$, stage II with a CAL from 3 to $4 \mathrm{~mm}$, and stage III with a CAL $\geq 5 \mathrm{~mm}$. The extent of periodontal disease can be considered localized if less than $30 \%$ of the sites are affected and generalized if more than $30 \%$ of the sites are involved [4].

The periodontitis has multiple determinants. Systemic diseases and conditions that affect periodontal supporting tissues, such as diabetes mellitus, nicotine dependence, or arthritis, can worsen periodontal deterioration [5]. On the other hand, poor oral hygiene generates accumulation of dental plaque, which first leads to gingivitis. Subsequently, the chronification of gingivitis causes a destruction of the tissues that support the teeth and finally periodontitis appears [6]. Hence, oral hygiene instructions for self-care are important to preserve periodontal health as well as mechanical or chemotherapeutic removal of dental plaque to 
minimize disease activity. It has been pointed out that the difficulty in modifying oral hygiene habits may be due to lack of motivation or problems with the implementation of prescribed oral hygiene procedures [7].

Depressive disorders are related to a decrease in oral healthcare consultations, as well as an increased risk of periodontal disease and tooth loss. The findings have strong implications throughout life, since early-onset mental disorders increase their potential to negatively impact oral health over time [8]. In addition, negligence in oral hygiene during periods of depression is associated with the loss of connective tissue attachment and tooth [9]. However, scientific evidence for this effect of depression on periodontitis is weak [5]. It is worth mentioning that, in a systematic review of the literature and meta-analysis on the association between depression and periodontitis, Araujo et al. [10] found a great heterogeneity in reported effect sizes and could not conclude that there was a significant association between depression and periodontitis.

As the effect and mechanism of action of depression on periodontitis are not clear, the objective of this study is to test a predictive model for CAL including depressive symptomatology, oral hygiene habits, and dental plaque accumulation. This hypothetical model proposes that CAL is a direct effect of a greater dental plaque accumulation and an indirect effect of greater depressive symptomatology and worse oral hygiene habits. The first hypothesis to specify the model is that depressive symptomatology has a direct effect on oral hygiene habits [8], as well as an indirect effect on dental plaque (mediated by oral hygiene habits) and on CAL (mediated by the 2 previous variables, that is, oral hygiene and dental plaque) $[7,11]$. In other words, greater levels of depressive symptoms determine worse oral hygiene habits due to depressive apathy and neglect in personal care. Likewise, greater depressive symptoms have an indirect effect on the increased accumulation of bacterial plaque due to these poor oral hygiene habits. As a final consequence, this increased accumulation of bacterial plaque results in CAL; therefore, greater depressive symptoms also have an indirect effect on CAL. The second hypothesis is that oral hygiene habits have a direct effect on dental plaque and an indirect effect on CAL (mediated by the dental plaque accumulation) [6]. That is to say, worse oral hygiene habits determine greater bacterial plaque accumulation, and this consequent accumulation produces CAL; hence, worse oral hygiene habits have an indirect effect on CAL. Finally, it was stated that the dental plaque accumulation has a direct effect on CAL [12], that is, greater bacterial plaque accumulation results directly in greater CAL (Figure 1).

To enhance the attributable effects in this nonexperimental study, the hypothetical model is tested on 3 samples drawn from 3 different populations and on the sample that resulted from joining them. A population is defined by CAL or disease under study (dental patients with periodontitis). Another population is defined by depressive symptoms, which is one of the two risk factors considered (mental health patients with depression). In the third population, CAL and depressive symptoms have a natural prevalence and are not defining features (general population). This

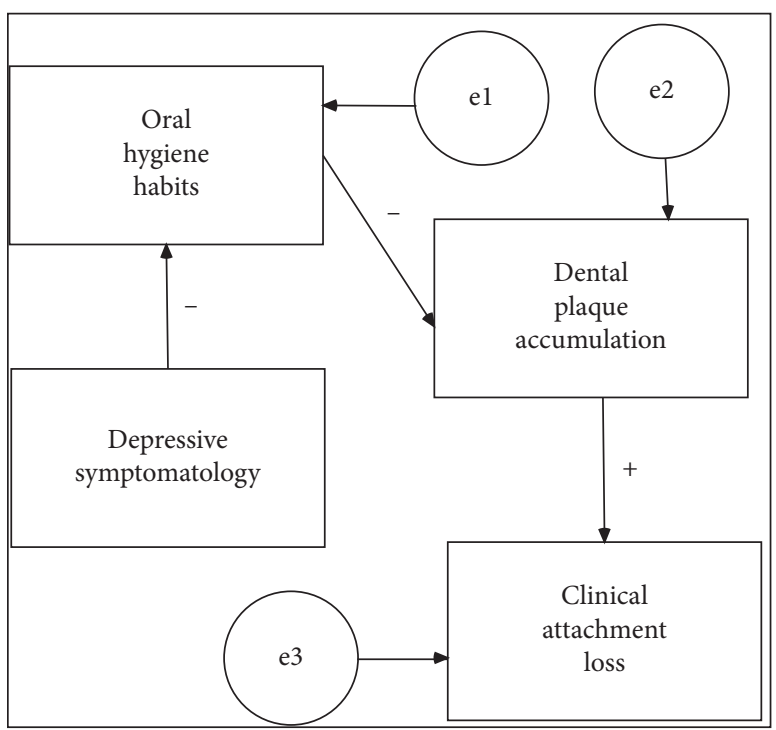

FIgure 1: Hypothetical model.

choice of population is made to enhance the effects attributable to depressive symptoms in a cross-sectional design (data collected at a single time point). The intention is to have a pooled sample in which people defined by clinical depression, CAL, and neither of these two clinical criteria can be distinguished; in such a way that the behavior of the parameters can be observed in each individual sample and when joining the three samples.

In relation to this design, the 3 samples collected are expected to differ significantly in the variables that define them (CAL and depressive symptoms), including in oral hygiene habits. The expectations are that the CAL will be greater in dental patients than in the other two populations with the greatest difference between dental patients and general population people [13], depressive symptoms are more frequent in mental health patients than in the other two populations with the greatest difference between depressive patients and general population people $[14,15]$, and oral hygiene habits are worse in both types of patients than in the general population [16]. Besides, it is intended that the 3 samples be as equivalent as possible in sociodemographic variables to control effects attributable to sociodemographic biases. It is expected that the specified direct and indirect effects are significant and the hypothetical model shows a good fit to the data in the 3 samples and pooled sample.

\section{Materials and Methods}

2.1. Design and Participants. This empirical research with base on its objectives was descriptive and correlational/ predictive and has a cross-sectional nonexperimental design [17]. Nonprobabilistic sampling was used. Convenience samples from 3 populations were taken. The common inclusion criteria for the 3 samples were as follows: residing in Monterrey or its metropolitan area (Nuevo León, Mexico), being an age between 35 and 65 years, and not receiving dental treatment or taking antibiotics or analgesics at the 
time of sampling. For the sample of dental patients, it was added to have received a diagnosis of periodontitis and not to have initiated periodontal treatment. For the sample of mental health patients, it was added to have received a formal diagnosis of depressive disorder, to have a total score in the Beck Depression Inventory-II $\geq 14[14,18]$, and not to be taking antidepressant medication or having less than 2 weeks of starting it. The exclusion criteria were as follows: being a pregnant woman, suffering from diabetes or some other systemic disease, using orthodontic appliances, and being a smoker. The purpose of these criteria was to select the ages with the highest prevalence of periodontitis $[19,20]$, excluding the subgroup of adults aged over 65 years due to its more specific health characteristics [21]. On the other hand, specific causes of risk for periodontal deterioration (systemic diseases, pregnancy, orthodontic appliances, and smoking) were eliminated [5]. In addition, it was intended that the periodontal treatment did not alter the natural evolution of the periodontitis in dental patients.

2.2. Procedures. The sample of dental patients was composed of 35 people who consulted at the Department of Periodontics of the Faculty of Dentistry of the Universidad Autónoma de Nuevo León (UANL). Once the patients were diagnosed with periodontitis and after checking the inclusion and exclusion criteria, they were invited to participate in the study. If the patient wanted to participate, he signed the informed consent form and answered the self-report questionnaire in an empty room.

The mental health sample was made up of 26 patients with depressive disorder, 16 (61.5\%) from the Psychological Services Unit of the UANL Faculty of Psychology, 6 (23.1\%) from the Department of Psychiatry at the University Hospital of UANL, and 4 (15.4\%) from the Psychiatric Rehabilitation Unit of the Secretary of Health of the State of Nuevo León. The department heads were contacted. Once permission was granted, the medical record base was reviewed. When a case was detected, the psychiatrist or psychologist informed the patient about the study. After leaving the consultation, if the patient wanted to participate, he/she signed the informed consent form, answered the questionnaire, and finally underwent periodontal evaluation.

The 29 participants in the general population sample were contacted, $23(79.3 \%)$ in workplaces and $6(20.7 \%)$ in family homes. After being informed about the study, they were asked to attend the Periodontics Clinic of the UANL Faculty of Dentistry to sign the informed consent, answer the questionnaire, and be submitted to periodontal evaluation.

First, the sample of dental patients was collected between February 2016 and May 2017. Then the sample of mental health patients was completed between August 2016 and November 2017. Finally, the general population sample was recruited between July and September 2018, and an attempt was made to match the previous two in demographic characteristics. This was done to minimize effects attributable to sociodemographic biases.
Unstimulated whole saliva samples were collected from the 2 samples of patients (dental and mental health patients) to determine the concentration of 3 biomarkers of proinflammatory activity using enzyme-linked immunosorbent assay (ELISA): matrix metalloproteinase-8 (MMP-8), interleukin-1 $\beta$ (IL-1 $\beta$ ), and interleukin-6 (IL-6). These data were used in another study [22].

2.3. Instruments of Assessment. Two periodontal parameters were assessed: CAL and plaque index. In addition, the participants answered a self-report questionnaire consisting of questions about sociodemographic information (sex, age, schooling, subjective socioeconomic status, civil status, and occupation) and 2 self-report scales. The scales were the following: Beck Depression Inventory-II (BDI-II) $[14,15,18]$ and Oral Hygiene Habits Scale (OHHS) [23].

The translation of BDI-II from English into Spanish by Sanz and Vázquez [15] was used. The BDI-II consists of 21 items that are answered by choosing 4 response options that are scored from 0 to 3 . Four levels of depression are distinguished based on the BDI-II total score: between 0 and 13 minimum, between 14 and 19 mild, between 20 and 28 moderate, and between 29 and 63 severe [14]. The BDI-II has been validated in Mexico. It has shown excellent internal consistency reliability in a sample of 420 medical students $(\alpha=0.92)$ and good in a community sample of 220 adults from Mexico City $(\alpha=0.87)$; a 3 -factor structure (negative attitude, performance difficulties, and somatic elements) showed the best fit to the data [18].

OHHS was developed in Mexico. It consists of 8 direct items with 5 response options that are scored from 0 to 4 . By adding the scores obtained in the items and dividing by 8 , the OHHS total score is obtained in a continuum from 0 to 4 . Higher score reflects better oral hygiene habits. There are 3 levels of oral hygiene habits based on the OHHS total score: between 0 and $0.99 \mathrm{bad}$, between 1 and 2.124 regular, and between 2.125 and 4 good. In Mexico, its internal consistency reliability was good (ordinal $\alpha=0.83$ among 256 adults in the general population and 0.87 among 240 dental patients) and it had 2-factor structure: dental brushing and flossing [23].

For the periodontal evaluation, the $15 \mathrm{~mm}$ North Carolina periodontal probe was used. The evaluation was performed by a single examiner. It was a full mouth examination. CAL was measured by the distance in millimeters between the cementoenamel line and the bottom of the periodontal pocket. In each dental piece, 6 sites were evaluated ( 3 vestibular and 3 palatine or lingual). The value reported per participant corresponds to the average of sites with CAL $(\geq 1 \mathrm{~mm})$. CAL was classified into 4 ordered categories: without $\mathrm{CAL}=0 \mathrm{~mm}$, stage $\mathrm{I}=$ between 1 and $2 \mathrm{~mm}$, stage II = between 3 and $4 \mathrm{~mm}$, and stage III $\geq 5 \mathrm{~mm}$ [4].

The plaque index assesses the amount of dental plaque visible on the vestibular and lingual surfaces of all teeth, except the third molars. The bacterial plaque developer solution was used to define cumulative amounts of plaque with criteria from 0 to 5 [24]. Once the values of the 
individual teeth are recorded, they are added and divided by the number of teeth examined to obtain the plaque index of each patient.

2.4. Statistical Analysis. Data analysis was performed with the SPSS version 24, AMOS version 16, and Microsoft Excel 2013. The 2-tailed tests with a significance level of 0.05 were computed. Due to the incidental nature of the samples, the randomness of the data sequence (in its order of sample collection) was tested through the Wald-Wolfowitz runs test for randomness; this was done to justify the use of inferential statistics.

In the sample description, the differences among the means in the numerical variables of the 3 samples were tested using analysis of variance (ANOVA). The assumption of normal distribution in each sample was tested through the Shapiro-Wilk test and the assumption of the equality of variances through Levene's test. When equality of variances could not be assumed, Welch's correction was used. The differences among the medians in the ordinal variables of 3 samples were tested using the Kruskal-Wallis test. The homogeneity among 3 samples regarding their distribution of frequencies in each categorical variable was tested using Pearson's chi-square test.

The internal consistency reliability among items composing each psychometric scales (BDI-II and OHHS) was verified in 3 samples using the ordinal omega coefficient (ordinal $\omega$ ). This coefficient does not require compliance with the assumption of tau-equivalent items (equivalent measurement weights between the items). Moreover, its calculation is based on measurement weights computed from the polychoric correlation matrix [25]. Precisely, this type of correlation is considered more suitable for ordinal variables, such as Likert-type items, than Pearson's productmoment correlation [26]. The measurement weights were estimated by the weighted least squares method, which is also considered more suitable for these types of variables [27], and polychoric correlations by the 2-step maximumlikelihood method. It was interpreted that values of ordinal $\omega$ between 0.70 and 0.79 reflect an acceptable level of reliability, between 0.80 and 0.89 good, and $\geq 0.90$ excellent [28].

The hypothetical model was tested using path analysis. This technique was chosen instead of modeling structural equations to not include the measurement models of each variable due to the sample size limitation [29]. However, the reliability of the measurement models (items composing of each scale) of depressive symptomatology and oral hygiene habits was checked by the ordinal omega coefficient [28]. The assumption of multivariate normality of the 4 variables included in the model was verified by Mardia's asymmetry and kurtosis tests. The punctual estimation of parameters was performed through maximum-likelihood method. Due to the limited sample size, the standard error and $95 \%$ confidence interval for each parameter were calculated by parametric bootstrapping (Monte Carlo method) with the simulation of 10,000 samples, since data showed a good approximation to multivariate normality [30, 31]. The goodness of fit was assessed using 5 indices: likelihood ratio chi-square test $\left(\chi^{2}\right)$, Bollen-Stine's bootstrap probability value with the simulation of 2,000 random samples (BS bootstrap $p$ ), relative or normed chi-square $\left(\chi^{2} / \mathrm{df}\right)$, goodness-of-fit index (GFI), and root mean square of error of approximation (RMSEA). $P\left(\chi^{2}>_{1-\alpha} \chi_{\text {df }}^{2}\right)$ and BS bootstrap $p$ values $>0.10, \chi^{2} / \mathrm{df} \leq 2, \mathrm{GFI} \geq 0.95$, and $p$ value $>0.10$ for $\mathrm{H}_{0}$ : RMSEA $\leq 0.05$ shows a good fit. On the other hand, $p\left(\chi^{2}>_{1-\alpha} \chi_{\mathrm{df}}^{2}\right)$ and BS $p$ values $>0.05, \chi^{2} / \mathrm{df} \leq 3, \mathrm{GFI} \geq 0.90$, and $p$ value $>0.05$ for $\mathrm{H}_{0}:$ RMSEA $\leq 0.05$ reflects an acceptable fit [29].

\section{Results}

3.1. Testing Randomness. The null hypothesis of randomness was supported for the sequence of data (in its order of sample collection) by the runs test with a significance level of 0.05 for all variables in the 3 samples, except for item 9 on suicidal ideation in the general population sample because it was a constant $(0=$ "never") (Table 1$)$.

\subsection{Internal Consistency Reliability of Psychosocial Variables.} Table 2 shows the levels of internal consistency reliability for the 8 items composing of the OHHS and the 21 items composing of the BDI-II, which varied from good (ordinal $\omega \geq 0.80$ ) to excellent (ordinal $\omega \geq 0.90$ ).

3.3. Description of the Sociodemographic and Clinical Variables. The frequency of participants was statistically equivalent among the 3 samples (one-sample chi-square test: $\chi^{2}[2]=1.40$, asymptotic $p$ value $\left.=0.497\right)$. Table 3 shows the frequency distributions of the sociodemographic variables (sex, age, schooling, subjective socioeconomic status, civil status, and occupation), oral clinical variables (classifications of CAL and plaque index), and psychosocial variables (levels of depressive symptomatology and oral hygiene habits) in the 3 samples, as well as the statistical comparison of each variable among the 3 samples.

According to the claim of equivalence in sociodemographic variables to avoid biases attributable to these variables, the frequencies of both sexes were statistically equivalent among the 3 samples (one-sample chi-square test: $\chi^{2}[2]=0.86$, asymptotic $p$ value $\left.=0.650\right)$. Consequently, the sex ratio in the pooled sample (binomial test for null hypothesis $\pi=0.5$ : two-tailed $p$ value $=0.916$ ) showed that there were half men and half women in each sample. Also, the frequencies of the 5 categories of civil status were statistically equivalent among the 3 samples (chi-square test for homogeneity: $\chi^{2}[8]=11.29$, exact two-tailed $p$ value $=0.180)$, as well as the levels of schooling and SSES (Kruskal-Wallis test: $\mathrm{H}[2]=2.72, p$ value $=0.257$ and $\mathrm{H}$ $[2]=4, p$ value $=0.136$, respectively) and the mean age (oneway between-group ANOVA: $F[2,86]=1.72, p$ val$\mathrm{ue}=0.186$ ). The civil status mode corresponded to the category of "married" marital status with two-thirds of the sample. The median schooling corresponded to "high school" level and SSES to "middle-middle" social stratus. The average age was 47 years (Table 3 ). 
TABLE 1: Runs test for the randomness of the data sequence.

\begin{tabular}{|c|c|c|c|c|c|c|c|c|c|c|c|c|}
\hline \multirow[b]{2}{*}{ Variable } & \multicolumn{4}{|c|}{ DPS $(n=35)$} & \multicolumn{4}{|c|}{ MHS $(n=26)$} & \multicolumn{4}{|c|}{ GPS $(n=29)$} \\
\hline & $n_{0}$ & $n_{1}$ & $R$ & $\begin{array}{c}p \\
\text { value }\end{array}$ & $n_{0}$ & $n_{1}$ & $R$ & $\begin{array}{c}p \\
\text { value }\end{array}$ & $n_{0}$ & $n_{1}$ & $R$ & $\begin{array}{c}p \\
\text { value }\end{array}$ \\
\hline BDI-1 & 31 & 4 & 9 & 0.845 & 16 & 10 & 15 & 0.533 & 26 & 3 & 7 & 0.836 \\
\hline BDI-2 & 28 & 7 & 12 & 1 & 13 & 13 & 14 & 1 & 26 & 3 & 7 & 0.836 \\
\hline BDI-3 & 32 & 3 & 7 & 0.858 & 17 & 9 & 13 & 1 & 28 & 1 & 3 & 1 \\
\hline BDI-4 & 29 & 6 & 12 & 0.559 & 17 & 9 & 11 & 0.517 & 27 & 2 & 3 & 0.071 \\
\hline BDI-5 & 27 & 8 & 12 & 0.638 & 18 & 8 & 14 & 0.469 & 23 & 6 & 7 & 0.050 \\
\hline BDI-6 & 33 & 2 & 5 & 1 & 18 & 8 & 11 & 0.640 & 28 & 1 & 3 & 1 \\
\hline BDI-7 & 28 & 7 & 11 & 0.580 & 19 & 7 & 11 & 1 & 26 & 3 & 7 & 0.836 \\
\hline BDI-8 & 23 & 12 & 17 & 1 & 15 & 11 & 15 & 0.684 & 22 & 7 & 8 & 0.055 \\
\hline BDI-9 & 34 & 1 & 3 & 1 & 15 & 11 & 15 & 0.684 & 0 & 29 & 1 & - \\
\hline BDI-10 & 30 & 5 & 9 & 0.854 & 10 & 16 & 15 & 0.533 & 26 & 3 & 7 & 0.836 \\
\hline BDI-11 & 30 & 5 & 11 & 0.550 & 18 & 8 & 13 & 0.834 & 26 & 3 & 7 & 0.836 \\
\hline BDI-12 & 30 & 5 & 9 & 0.854 & 13 & 13 & 14 & 1 & 27 & 2 & 5 & 1 \\
\hline BDI-13 & 32 & 3 & 7 & 0.858 & 16 & 10 & 14 & 0.834 & 28 & 1 & 3 & 1 \\
\hline BDI-14 & 32 & 3 & 4 & 0.024 & 16 & 10 & 16 & 0.294 & 27 & 2 & 5 & 1 \\
\hline BDI-15 & 18 & 17 & 20 & 0.615 & 17 & 9 & 14 & 0.661 & 13 & 16 & 16 & 0.854 \\
\hline BDI-16 & 19 & 16 & 19 & 0.861 & 11 & 15 & 14 & 1 & 16 & 13 & 13 & 0.445 \\
\hline BDI-17 & 26 & 9 & 12 & 0.378 & 18 & 8 & 10 & 0.358 & 27 & 2 & 5 & 1 \\
\hline BDI-18 & 28 & 7 & 13 & 0.856 & 15 & 11 & 12 & 0.544 & 24 & 5 & 9 & 1 \\
\hline BDI-19 & 26 & 9 & 13 & 0.649 & 12 & 14 & 12 & 0.551 & 23 & 6 & 13 & 0.272 \\
\hline BDI-20 & 13 & 22 & 18 & 0.852 & 14 & 12 & 16 & 0.428 & 18 & 11 & 14 & 0.839 \\
\hline BDI-21 & 31 & 4 & 9 & 0.845 & 16 & 10 & 15 & 0.533 & 26 & 3 & 7 & 0.836 \\
\hline BDI-22 & 28 & 7 & 12 & 1 & 13 & 13 & 14 & 1 & 26 & 3 & 7 & 0.836 \\
\hline BDI-II & 15 & 20 & 14 & 0.164 & 14 & 12 & 16 & 0.428 & 18 & 11 & 12 & 0.317 \\
\hline $\begin{array}{l}\text { OHHS- } \\
1\end{array}$ & 14 & 21 & 20 & 0.477 & 11 & 15 & 16 & 0.414 & 11 & 18 & 14 & 0.839 \\
\hline $\begin{array}{l}\text { OHHS- } \\
2\end{array}$ & 22 & 13 & 17 & 1 & 15 & 11 & 15 & 0.684 & 14 & 15 & 15 & 1 \\
\hline $\begin{array}{l}\text { OHHS- } \\
3\end{array}$ & 15 & 20 & 14 & 0.164 & 12 & 14 & 17 & 0.233 & 19 & 10 & 16 & 0.525 \\
\hline $\begin{array}{l}\text { OHHS- } \\
4\end{array}$ & 20 & 15 & 23 & 0.114 & 11 & 15 & 16 & 0.414 & 11 & 18 & 14 & 0.839 \\
\hline $\begin{array}{l}\text { OHHS- } \\
5\end{array}$ & 29 & 6 & 9 & 0.437 & 16 & 10 & 14 & 0.834 & 20 & 9 & 12 & 0.664 \\
\hline $\begin{array}{l}\text { OHHS- } \\
6\end{array}$ & 22 & 13 & 19 & 0.591 & 15 & 11 & 16 & 0.414 & 20 & 9 & 12 & 0.664 \\
\hline $\begin{array}{l}\text { OHHS- } \\
7\end{array}$ & 33 & 2 & 3 & 0.059 & 25 & 1 & 3 & 1 & 22 & 7 & 8 & 0.055 \\
\hline $\begin{array}{l}\text { OHHS- } \\
8\end{array}$ & 32 & 3 & 7 & 0.858 & 18 & 8 & 12 & 1 & 14 & 15 & 10 & 0.056 \\
\hline OHHS & 16 & 19 & 15 & 0.300 & 14 & 12 & 18 & 0.065 & 19 & 10 & 10 & 0.097 \\
\hline CAL & 19 & 16 & 14 & 0.166 & 12 & 14 & 12 & 0.551 & 9 & 20 & 10 & 0.188 \\
\hline PI & 17 & 18 & 17 & 0.732 & 16 & 10 & 16 & 0.294 & 14 & 15 & 14 & 0.706 \\
\hline
\end{tabular}

Note. Samples: DPS $=$ sample of dental patients with periodontitis, MHS = sample of mental health patients with depressive symptomatology, and GPS $=$ general population sample. Statistics: $n_{0}=$ number of cases $<$ arithmetic mean, $n_{1}=$ number of cases $\geq$ arithmetic mean, $R=$ number of runs, and $p$ value $=$ two-tailed exact probability value. Variables: BDI-i $=$ item $i$ ( 1 to 21$)$ of the Beck Depression Inventory-II, BDI-II = BDI-II total score, OHHS- $\mathrm{i}=\mathrm{item} i$ (1 to 8$)$ of the Oral Hygiene Habits Scale, OHHS=OHHS total score, $\mathrm{CAL}=$ clinical attachment loss, and $\mathrm{PI}=$ plaque index.

However, there were differences in occupation (chisquare test for homogeneity: $\chi^{2}[4]=11.64$, exact two-tailed $p$ value $=0.019$ ). There were more homemakers in the sample of mental health patients compared to that of the general population; in turn, there were more unskilled manual workers and low-skilled technicians in the dental patient sample compared to the mental health patient
TABLE 2: Internal consistency reliability through coefficient ordinal omega.

\begin{tabular}{lccc}
\hline Scale & DPS $(n=35)$ & MHS $(n=26)$ & GPS $(n=29)$ \\
\hline BDI-II & 0.800 & 0.881 & $0.909^{*}$ \\
OHHS & 0.851 & 0.932 & 0.901 \\
\hline
\end{tabular}

Note. Samples: DPS $=$ sample of dental patients with periodontitis, MHS = sample of mental health patients with depressive symptomatology, and GPS = general population sample. Variables: BDI-II = Beck Depression Inventory-II and OHHS = Oral Hygiene Habits Scale. ${ }^{*}$ Without item 9 (thoughts or wishes of suicide) because it was a constant $(0=$ "never").

sample (Table 3). The strength of the association between the type of sample and occupation was small (Cramer's $V=0.27$ ).

There was heterogeneity of variances in CAL and plaque index among the 3 samples by Levene's test, and thus, Welch's ANOVA was used. This omnibus test rejected the null hypothesis that means were equal among the 3 samples. The effect of sample type on the oral health variable was large through omega squared $\left(\omega^{2}>0.14\right)$. The Games-Howell test for multiple pairwise comparisons showed that mean of dental patients was higher than means of mental health patients and general population persons in both variables (Table 4).

The means in OHHS total score (oral hygiene habits) were equivalent among the 3 groups with a level of significance set at 0.05 , but their difference would be significant if the level of significance is set at $0.01(F[2,87]=2.90, p$ value $=0.060$ ). The effect of the group type on oral hygiene habits was small $\left(0.06>\omega^{2}>0.01\right)$. When performing multiple pairwise comparisons through Tukey's test, there was no significant difference in a 2-tailed test with a level of significance set at 0.05 , but there was a significant difference using Fisher's least significant difference (LSD) test. The mean of the dental patients was higher than the mean of the general population persons (Fisher's LSD: $t[87]=2.29, p$ value $=0.025)$. The comparison of means in the total BDI-II score was carried out through Welch's ANOVA, due to the unfulfillment of the variance homogeneity assumption. The difference was significant and the effect size was very large $\left(\omega^{2}>0.50\right)$. The mean in depressive symptomatology of mental health patients was higher than the means of the other 2 groups, between which the mean difference was not significant (Table 4).

3.4. Testing Model. Table 5 shows the descriptive statistics and normality test in the sample of 35 dental patients. The assumption of multivariate normality was fulfilled (Mardia's multivariate skewness $=4.42, Z=25.81$, and $p$ value $=0.172$; Mardia's multivariate kurtosis $=21.83, \chi^{2}[20, N=35]=-$ 0.93 , and $p$ value $=0.355$ ) .

Figure 2 shows the model estimated in the sample of dental patients. Only the direct effect of the plaque index on CAL was significant (Table 6). Its size was medium. The goodness of fit of the model was good based on 4 indices $\left(\chi^{2}\right.$ $[3, N=35]=4.13, \quad p$ value $=0.241 ; \quad$ BS bootstrap $p$ value $=0.253 ; \chi^{2} / \mathrm{df}=1.377 ;$ and $\mathrm{RMSEA}=0.110,90 \% \mathrm{CI}(0$, $0.325), \quad p$ value $=0.283$ under null hypothesis $\mathrm{H}_{0}$ : 
TABLE 3: Sociodemographic and clinical variables and statistical comparison among the 3 samples.

\begin{tabular}{|c|c|c|c|c|c|c|}
\hline Variable & & $\begin{array}{c}\text { DPS } \\
n(\%)\end{array}$ & $\begin{array}{l}\text { MHS } \\
n(\%)\end{array}$ & $\begin{array}{c}\text { GPS } \\
n(\%)\end{array}$ & Total & $p$ value \\
\hline Sample & & $35(38.9 \%)$ & $26(28.9 \%)$ & $29(32.2 \%)$ & $90(100 \%)$ & $\begin{array}{c}0.497 \\
\chi^{2} \text { test }\end{array}$ \\
\hline Sex & $\begin{array}{c}\text { Women } \\
\text { Men }\end{array}$ & $\begin{array}{l}16(45.7 \%) \\
19(54.3 \%)\end{array}$ & $\begin{array}{l}15(57.7 \%) \\
11(42.3 \%)\end{array}$ & $\begin{array}{l}15(51.7 \%) \\
14(48.3 \%)\end{array}$ & $\begin{array}{l}46(51.1 \%) \\
44(48.9 \%)\end{array}$ & $\begin{array}{l}\chi \\
\chi^{2} \text { test }\end{array}$ \\
\hline Age & $\begin{array}{l}35-39 \\
40-49 \\
50-59 \\
60-65 \\
\end{array}$ & $\begin{array}{c}6(17.1 \%) \\
14(40 \%) \\
12(34.3 \%) \\
3(8.6 \%) \\
\end{array}$ & $\begin{array}{c}8(30.8 \%) \\
12(46.2 \%) \\
5(19.2 \%) \\
1(3.8 \%) \\
\end{array}$ & $\begin{array}{c}5(17.2 \%) \\
11(37.9 \%) \\
12(41.4 \%) \\
1(3.4 \%) \\
\end{array}$ & $\begin{array}{c}19(21.1 \%) \\
37(41.1 \%) \\
29(32.2 \%) \\
5(5.6 \%) \\
\end{array}$ & $\begin{array}{c}0.186 \\
\text { ANOVA }\end{array}$ \\
\hline Schooling & $\begin{array}{c}\text { Primary } \\
\text { Secondary } \\
\text { High school } \\
\text { Vocational } \\
\text { Bachelor } \\
\text { Postgraduate }\end{array}$ & $\begin{array}{c}5(14.3 \%) \\
9(25.7 \%) \\
6(17.1 \%) \\
7(20 \%) \\
7(20 \%) \\
1(2.9 \%) \\
\end{array}$ & $\begin{array}{c}3(11.5 \%) \\
10(38.5 \%) \\
1(3.8 \%) \\
5(19.2 \%) \\
5(19.2 \%) \\
2(7.7 \%) \\
\end{array}$ & $\begin{array}{c}2(6.9 \%) \\
4(13.8 \%) \\
7(24.1 \%) \\
5(17.2 \%) \\
10(34.5 \%) \\
1(3.4 \%) \\
\end{array}$ & $\begin{array}{cl}10 & (11.1 \%) \\
23 & (25.6 \%) \\
14 & (15.6 \%) \\
17 & (18.9 \%) \\
22 & (24.4 \%) \\
4 & (4.4 \%) \\
\end{array}$ & $\begin{array}{c}0.257 \\
\text { Kruskal-Wallis test }\end{array}$ \\
\hline SSES & $\begin{array}{c}\text { Low } \\
\text { Middle-low } \\
\text { Middle-middle } \\
\end{array}$ & $\begin{array}{c}2(5.7 \%) \\
12(34.3 \%) \\
21(60 \%) \\
\end{array}$ & $\begin{array}{c}2(7.7 \%) \\
13(50 \%) \\
11(42.3 \%) \\
\end{array}$ & $\begin{array}{c}1(3.4 \%) \\
8(27.6 \%) \\
20(69 \%) \\
\end{array}$ & $\begin{array}{c}5(5.6 \%) \\
33(36.7 \%) \\
52(57.8 \%) \\
\end{array}$ & $\begin{array}{c}0.136 \\
\text { Kruskal-Wallis test }\end{array}$ \\
\hline Civil status & $\begin{array}{c}\text { Married } \\
\text { Single } \\
\text { Divorced or separated } \\
\text { Cohabitating } \\
\text { Widow } \\
\end{array}$ & $\begin{aligned} & 25(71.4 \%) \\
& 2(5.7 \%) \\
& 3(8.6 \%) \\
& 3(8.6 \%) \\
& 2(5.7 \%) \\
&\end{aligned}$ & $\begin{array}{l}13(50 \%) \\
6(23.1 \%) \\
5(19.2 \%) \\
1(3.8 \%) \\
1(3.8 \%) \\
\end{array}$ & $\begin{array}{c}23(79.3 \%) \\
4(13.8 \%) \\
1(3.4 \%) \\
1(3.4 \%) \\
0(0 \%) \\
\end{array}$ & $\begin{array}{c}61(67.8 \%) \\
12(13.3 \%) \\
9(10 \%) \\
5(5.6 \%) \\
3(3.3 \%) \\
\end{array}$ & $\begin{array}{c}0.180 \\
\chi^{2} \text { test }\end{array}$ \\
\hline Occupation & $\begin{array}{l}\text { White-collar worker } \\
\text { Homemaker } \\
\text { Blue-collar worker } \\
\text { Others }\end{array}$ & $\begin{array}{c}15^{\mathrm{a}}(42.9 \%) \\
11^{\mathrm{a}, \mathrm{b}}(31.4 \%) \\
8^{\mathrm{a}}(22.9 \%) \\
2^{\mathrm{a}}(5.7 \%)\end{array}$ & $\begin{array}{c}13^{\mathrm{a}}(50 \%) \\
12^{\mathrm{b}}(46.2 \%) \\
0^{\mathrm{b}}(0 \%) \\
1^{\mathrm{a}}(3.8 \%)\end{array}$ & $\begin{array}{c}17^{\mathrm{a}}(58.6 \%) \\
3^{\mathrm{a}}(10.3 \%) \\
4^{\mathrm{a}, \mathrm{b}}(13.8 \%) \\
5^{\mathrm{a}}(17.2 \%)\end{array}$ & $\begin{array}{c}45(50 \%) \\
26(28.9 \%) \\
12(13.3 \%) \\
8(8.9 \%)\end{array}$ & $\begin{array}{c}0.015 \\
\chi^{2} \text { test }\end{array}$ \\
\hline Classification of CAL & $\begin{array}{c}\text { Without CAL } \\
\text { Stage I } \\
\text { Stage II } \\
\text { Stage III }\end{array}$ & $\begin{array}{c}0(0 \%) \\
0(0 \%) \\
17(48.6 \%) \\
18(51.4 \%) \\
\end{array}$ & $\begin{array}{c}0(0.0 \%) \\
0(0 \%) \\
24(92.3 \%) \\
2(7.7 \%)\end{array}$ & $\begin{array}{c}6(20.7 \%) \\
1(3.4 \%) \\
15(51.7 \%) \\
7(24.1 \%) \\
\end{array}$ & $\begin{array}{c}6(6.7 \%) \\
1(1.1 \%) \\
56(62.2 \%) \\
27(30 \%) \\
\end{array}$ & $\begin{array}{c}0.001 \\
\text { Kruskal-Wallis test }\end{array}$ \\
\hline Classification of plaque index & $\begin{array}{l}\text { Low } \\
\text { High }\end{array}$ & $\begin{array}{c}0^{\mathrm{a}}(0 \%) \\
35^{\mathrm{a}}(100 \%)\end{array}$ & $\begin{array}{c}0^{\mathrm{a}}(0 \%) \\
26^{\mathrm{a}}(100 \%) \\
\end{array}$ & $\begin{array}{l}10^{\mathrm{b}}(34.5 \%) \\
19^{\mathrm{b}}(65.5 \%)\end{array}$ & $\begin{array}{l}10(11.1 \%) \\
80(88.9 \%) \\
\end{array}$ & $\begin{array}{l}<0.001 \\
\chi^{2} \text { test } \\
\end{array}$ \\
\hline Level of depressive symptomatology & $\begin{array}{l}\text { Minimal } \\
\text { Mild } \\
\text { Moderate } \\
\text { Severe }\end{array}$ & $\begin{array}{c}35(100 \%) \\
0(0 \%) \\
0(0 \%) \\
0(0 \%)\end{array}$ & $\begin{array}{c}0(0 \%) \\
8(30.8 \%) \\
7(26.9 \%) \\
11(42.3 \%)\end{array}$ & $\begin{array}{c}29(100 \%) \\
0(0 \%) \\
0(0 \%) \\
0(0 \%)\end{array}$ & $\begin{aligned} 64 & (71.1 \%) \\
8 & (8.9 \%) \\
7 & (7.8 \%) \\
11 & (12.2 \%)\end{aligned}$ & $\begin{array}{c}<0.001 \\
\text { Kruskal-Wallis test }\end{array}$ \\
\hline Classification of oral hygiene habits & $\begin{array}{l}\text { Bad } \\
\text { Regular } \\
\text { Good }\end{array}$ & $\begin{array}{c}13(37.1 \%) \\
20(57.1 \%) \\
2(5.7 \%)\end{array}$ & $\begin{array}{c}10(38.5 \%) \\
15(57.7 \%) \\
1(3.8 \%)\end{array}$ & $\begin{array}{c}7(24.1 \%) \\
16(55.2 \%) \\
6(20.7 \%) \\
\end{array}$ & $\begin{array}{c}3033.3 \% \\
51(56.7 \%) \\
9(10 \%)\end{array}$ & $\begin{array}{c}0.107 \\
\text { Kruskal-Wallis test }\end{array}$ \\
\hline
\end{tabular}

Note. Samples: DPS = sample of dental patients with periodontitis, MHS = sample of mental health patients with depressive symptomatology, and GPS = general population sample. Variables: age $=$ the 4 age ranges shown in the table are used for descriptive purposes, since the mean comparisons are made with the quantitative variable "years of age" using the one-way between-group analysis of variance (ANOVA); SSES = subjective socioeconomic status; occupation = white-collar worker (clerk, receptionist, telephone operator, salesperson, and supervisor), homemaker (housewife and househusband), and blue-collar worker including both unskilled manual worker (cleaning worker, waiter, stevedore, assembly line worker, keeper, and security guard) and lowskilled technician (mason, painter, plumber, electrician, carpenter, glazier, hauler, heavy equipment operator, and clinical assistant), and others (selfemployed worker, unemployed, and retired); classification of $\mathrm{CAL}=$ classification of clinical attachment loss (without CAL $=0 \mathrm{~mm}$, stage $\mathrm{I}=1$ to $2 \mathrm{~mm}$, stage $\mathrm{II}=3$ to $4 \mathrm{~mm}$, and stage III $=5 \mathrm{~mm}$ or more); classification of plaque index = classification of the Turesky-Gilmore-Glickman plaque index (low: 0 to 1 and high: 2 to 5); level of depressive symptomatology (minimal = BDI-II total score from 0 to 13, mild 14 to 19, moderate from 20 to 28 , and severe from 29 to 63 ); and classification of oral hygiene habits (bad = OHHS total score from 0 to 0.999 , regular from 1 to 2,124, and good from 2,125 to 4). Statistics: $n=$ absolute frequency, $p$ value $=$ probability value for a 2 -tailed test, and $a, b=$ each subscript letter denotes a subset of categories whose column proportions do not differ significantly from each other at the 0.05 level applying Bonferroni's correction.

RMSEA $\leq 0.05)$, and acceptable based on one $(\mathrm{GFI}=0.946)$. When reviewing modification indices for the fit improvement, there was no suggestion.

Table 5 shows the descriptive statistics and normality test in the sample of 26 mental health patients with depressive symptomatology. The assumption of multivariate normality was fulfilled (Mardia's multivariate skewness $=4.33$, $Z=18.75, \quad p \quad$ value $=0.538$; Mardia's multivariate kurtosis $=22.63, \chi^{2}[20, N=35]=-0.50, p$ value $=0.614$ ). Figure 3 shows the model estimated in this sample. As in the previous model, only the effect of plaque index on the CAL was significant (Table 6). Its size was medium. The 5 
TABLE 4: One-way analysis of variance for independent groups and multiple pairwise comparisons of means.

\begin{tabular}{|c|c|c|c|c|c|c|c|}
\hline \multirow{2}{*}{ Variable } & \multirow{2}{*}{ Sample } & \multirow{2}{*}{$M(95 \% \mathrm{CI})$} & \multirow{2}{*}{ Levene } & \multicolumn{2}{|c|}{ ANOVA } & \multirow{2}{*}{$\omega^{2}$} & \multirow{2}{*}{ Multiple comparisons } \\
\hline & & & & $F$ & $p$ & & \\
\hline \multirow{3}{*}{ CAL } & DPS & $4.56(4.45,4.68)$ & \multirow{3}{*}{$31.76^{* * *}$} & \multirow{3}{*}{ Welch 19.50} & \multirow{3}{*}{$<0.001$} & \multirow{3}{*}{0.185} & Games-Howell: \\
\hline & MHS & $4.05(3.90,4.21)$ & & & & & DPS $>$ \\
\hline & GPS & $3.27(2.56,3.97)$ & & & & & MHS = GPS \\
\hline \multirow{3}{*}{ Plaque index } & DPS & $2.84(2.68,3)$ & \multirow{3}{*}{$8.78^{* * *}$} & \multirow{3}{*}{ Welch 7.43} & \multirow{3}{*}{$<0.001$} & \multirow{3}{*}{0.179} & Games-Howell: \\
\hline & MHS & $2.74(2.58,2.90)$ & & & & & DPS $>$ \\
\hline & GPS & $2.21(1.92,2.51)$ & & & & & MHS = GPS \\
\hline \multirow{3}{*}{ OHHS total score } & DPS & $1.12(0.94,1.30)$ & \multirow{3}{*}{$1.27^{\mathrm{ns}}$} & \multirow{3}{*}{2.90} & \multirow{3}{*}{0.060} & \multirow{3}{*}{0.041} & Fisher: DPS > GPS \\
\hline & MHS & $1.18(0.88,1.48)$ & & & & & DPS $=$ MHS \\
\hline & GPS & $1.50(1.22,1.78)$ & & & & & MHS = GPS \\
\hline \multirow{3}{*}{ BDI-II total score } & DPS & $5.86(4.41,7.30)$ & \multirow{3}{*}{$19.07^{* * *}$} & \multirow{3}{*}{ Welch 63.05} & \multirow{3}{*}{$<0.001$} & \multirow{3}{*}{0.713} & Games-Howell: \\
\hline & MHS & $25.81(22,29.61)$ & & & & & MHS> \\
\hline & GPS & $3.69(2.36,5.02)$ & & & & & DPS = GPS \\
\hline
\end{tabular}

Note. Samples: DPS = sample of dental patients with periodontitis, MHS = sample of mental health patients with depressive symptomatology, and GPS $=$ general population sample. Levene $=$ testing statistic of Levene's test for equality of variance; $\mathrm{ns}=$ nonsignificant $=p$ value $>0.050$ and ${ }^{* * *} p$ value $\leq$ 0.001 or probability value under null hypothesis of equality of variances. ANOVA: $F=$ testing statistic for Fisher's one-way analysis of variance for independent groups, Welch = testing statistic of Welch's test for equality of means, and $p$ value = probability value under null hypothesis of equality of means. $\omega^{2}=$ omega-squared or effect size estimator. Multiple comparisons: groups whose means were statistically different by the Games-Howell test for multiple pairwise comparisons or Fisher's least significant difference test.

Table 5: Descriptive statistics and normality test in the sample of 35 dental patients.

\begin{tabular}{|c|c|c|c|c|c|c|c|c|c|c|}
\hline \multirow{2}{*}{ Sample } & \multirow{2}{*}{ Variable } & \multicolumn{6}{|c|}{ Descriptive statistics } & \multicolumn{3}{|c|}{ Shapiro-Wilk's test } \\
\hline & & Min & Max & Sk & $Z_{\mathrm{Sk}}$ & $K_{3}$ & $Z_{\mathrm{K} 3}$ & $W$ & $\mathrm{df}$ & $p$ \\
\hline \multirow{4}{*}{ Dental patient sample } & BDI-II & 0 & 13 & 0.162 & 0.391 & -1.228 & -1.483 & 0.922 & 35 & 0.016 \\
\hline & OHHS & 0.25 & 2.50 & 0.275 & 0.663 & -0.077 & -0.093 & 0.959 & 35 & 0.215 \\
\hline & CAL & 3.80 & 5.42 & 0.515 & 1.243 & 0.965 & 1.165 & 0.957 & 35 & 0.192 \\
\hline & PI & 2 & 3.72 & 0.181 & 0.436 & -0.947 & -1.144 & 0.971 & 35 & 0.463 \\
\hline \multirow{4}{*}{ Mental health patient sample } & BDI-II & 14 & 50 & 0.699 & 1.456 & -0.059 & -0.062 & 0.932 & 26 & 0.086 \\
\hline & OHHS & 0.25 & 3.50 & 1.045 & 2.176 & 1.676 & 1.744 & 0.905 & 26 & 0.020 \\
\hline & CAL & 3.21 & 4.78 & -0.536 & -1.116 & -0.044 & -0.046 & 0.958 & 26 & 0.353 \\
\hline & PI & 2.13 & 3.63 & 0.366 & 0.762 & -0.699 & -0.728 & 0.955 & 26 & 0.301 \\
\hline \multirow{5}{*}{ General population sample } & BDI-II & 0 & 11 & 0.902 & 1.983 & -0.251 & -0.276 & .868 & 29 & 0.002 \\
\hline & OHHS & 0.50 & 3.37 & 0.847 & 1.861 & 0.127 & 0.139 & .928 & 29 & 0.050 \\
\hline & CAL & 0 & 6 & -0.882 & -1.940 & -0.547 & -0.601 & .828 & 29 & $<0.001$ \\
\hline & $\mathrm{CAL}^{2}$ & 0 & 36 & 0.003 & 0.006 & -0.578 & -0.636 & .939 & 29 & 0.095 \\
\hline & PI & 0.83 & 3.56 & -0.244 & -0.537 & -1.014 & -1.114 & .954 & 29 & 0.235 \\
\hline
\end{tabular}

Note. Variables: BDI-II = total score in Beck Depression Inventory-II, OHHS = total score in Hygiene Habits Scale, CAL $=$ clinical attachment loss, $\mathrm{CAL}^{2}=$ clinical attachment loss values squared to correct negative skewness, and $\mathrm{PI}=$ plaque index. Statistics: Min $=\operatorname{minimum}, \mathrm{Max}=\operatorname{maximum}$, $\mathrm{Sk}=$ coefficient of skewness based on central moments, $Z_{\mathrm{Sk}}=$ standardized value of the coefficient of skewness, $K_{3}=$ excess kurtosis, $Z_{\mathrm{K} 3}=$ standardized value of excess kurtosis, $W=$ Shapiro-Wilk's testing statistic, $\mathrm{df}=$ degree of freedom, and $p$ value $=$ probability value under null hypothesis that empirical distribution follows a normal distribution.

goodness-of-fit indices evidenced a close fit to the data: $\chi^{2}[3$, $N=26]=1.86$, $p$ value $=0.601$; BS bootstrap $p$ value $=0.547$; $\chi^{2} / \mathrm{df}=0.621 ; \mathrm{GFI}=0.965 ;$ and $\mathrm{RMSEA}=0,90 \%$ CI $(0$, $0.281), \quad p$ value $=0.625$ under null hypothesis $\mathrm{H}_{0}$ : RMSEA $\leq 0.05$.

Table 5 shows the descriptive statistics and normality test in the sample of 29 participants from the general population. A mathematical transformation was applied to CAL, raising the squared scores to correct the negative skewness and achieve a normal distribution. The assumption of multivariate normality was fulfilled (Mardia's multivariate skewness $=4.85, Z=23.42$, $p$ value $=0.269$; Mardia's multivariate kurtosis $=22.64, \chi^{2}[20, N=35]=-0.53, \quad p$ value $=0.598$ ). Figure 4 shows the model estimated in this sample. Depressive symptomatology had no direct effect on oral hygiene habits, nor indirect effect (mediated by oral hygiene habits) on the dental plaque accumulation as in the previous 2 samples. Oral hygiene habits had a direct, negative, and large-size effect on the dental plaque accumulation and an indirect, negative, and medium-size effect on CAL. In addition, the dental plaque accumulation had a direct, positive, and large-size effect on CAL (squared scores) (Table 6). The model explained $29 \%$ of the variance of the plaque index and $41 \%$ of the variance of the CAL. The goodness of fit of this model was good based on 3 indices $\left(\chi^{2}\right.$ $[3, N=29]=6.15, p$ value $=0.105 ;$ BS bootstrap $p$ val$\mathrm{ue}=0.151$; and RMSEA $=0.193,90 \%$ CI $(0,0.414), p$ val$\mathrm{ue}=0.125)$, and acceptable based on 2 indices $\left(\chi^{2} / \mathrm{df}=2.048\right.$ and GFI $=0.908)$. When reviewing modification indices for the fit improvement, there was no suggestion. 


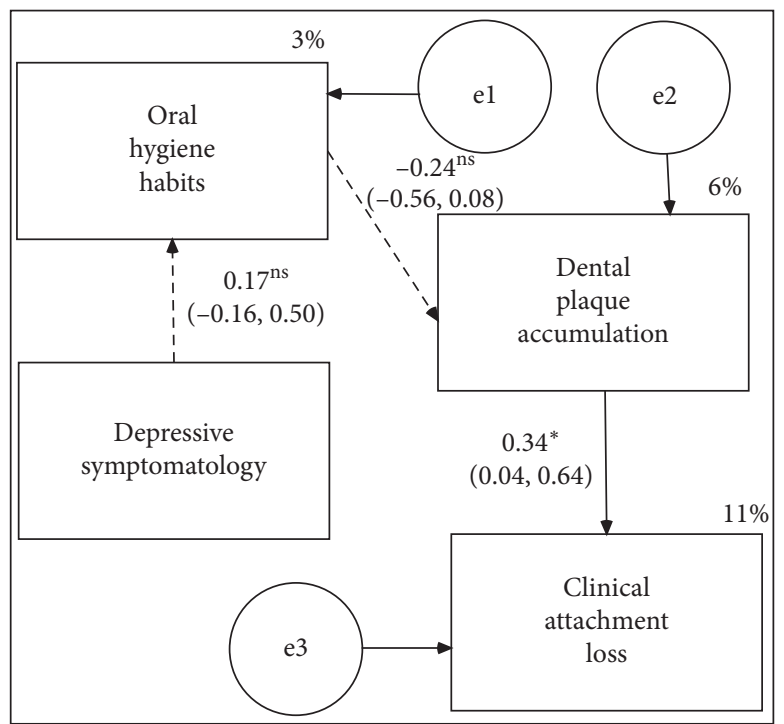

Figure 2: Maximum-likelihood parameter point estimates and 95\% Monte Carlo confidence intervals (with 10,000 bootstrap samples) in the sample of 35 dental patients.

TABLE 6: Standardized direct and indirect effects.

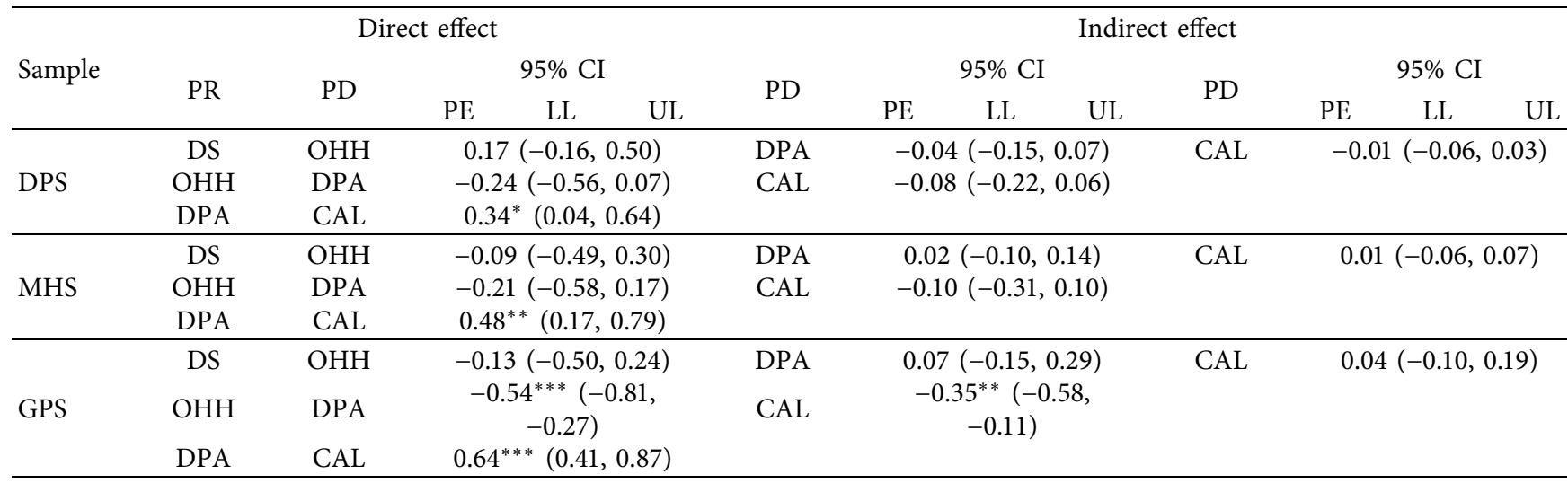

Note. Samples: DPS = sample of dental patients with periodontitis, MHS = sample of mental health patients with depressive symptomatology, and GPS = general population sample. Variables: $\mathrm{PR}=$ predictor, $\mathrm{PD}=$ predicted variable, $\mathrm{DS}=$ depressive symptomatology $(\mathrm{BDI}-\mathrm{II}$ total score), OHH $=$ oral hygiene habits (OHHS total score), DPA = dental plaque accumulation (plaque index), and CAL = clinical attachment loss. Statistics: $\mathrm{PE}=$ point estimation through the maximum-likelihood method and 2 -tailed probability value using $Z$-test: ${ }^{*} p$ value $\leq 0.05,{ }^{* *} p$ value $\leq 0.01,{ }^{* * *} p$ value $\leq 0.001,95 \% \mathrm{CI}=$ interval estimation with a confidence level of $95 \%$ through parametric (Monte Carlo) bootstrap method, LL= lower limit, and UL $=$ upper limit.

It should be noted that when the 3 samples were pooled, the direct effect of oral hygiene habits on dental plaque accumulation $(\widehat{\beta}=-0.43,95 \%$ CI $(-0.60,-0.27), Z=-5.05, p$ value $<0.001)$ and its indirect effect on CAL $(\beta=-0.27,95 \%$ CI $(-0.40,-0.14, Z=-4.06, p$ value $<0.001)$, as well as the direct effect of dental plaque accumulation on $\operatorname{CAL}(\widehat{\beta}=0.63$, $95 \%$ CI $(0.50,0.75), Z=9.63, p$ value $<0.001)$ were significant. As in previous models, depressive symptoms had no direct effect on oral hygiene habits $(\widehat{\beta}=-0.10,95 \%$ CI $(-0.31$, $0.10), Z=-0.99, p$ value $=0.322$, nor indirect effects on dental plaque accumulation or CAL. Goodness-of-fit indices varied from acceptable $\left(\chi^{2}[3, N=90]=7.37, p\right.$ value $=0.052$; Bollen-Stine bootstrap $p$ value $=0.060 ; \chi^{2} / \mathrm{df}=2.579$; and RMSEA $=0.133,90 \%$ CI $(0,0.253)$, $p$ value $=0.095)$ to good $(\mathrm{GFI}=0.959)$.

\section{Discussion}

The purpose of this research was to analyze the relationship between 4 variables, 2 psychosocial (depressive symptomatology and oral hygiene habits), and 2 oral health variables (plaque accumulation and CAL) in 3 different populations. On the one hand, the samples were extracted from 2 clinical populations, one defined by CAL (dental patients with chronic periodontitis) and another defined by depressive symptomatology (mental health patients). On the other hand, it was considered a population in which periodontal and depressive pathology were not distinctive features (general population). Before using inferential statistics to analyze the data, it was necessary to verify its randomness, since the sample data were collected through a 


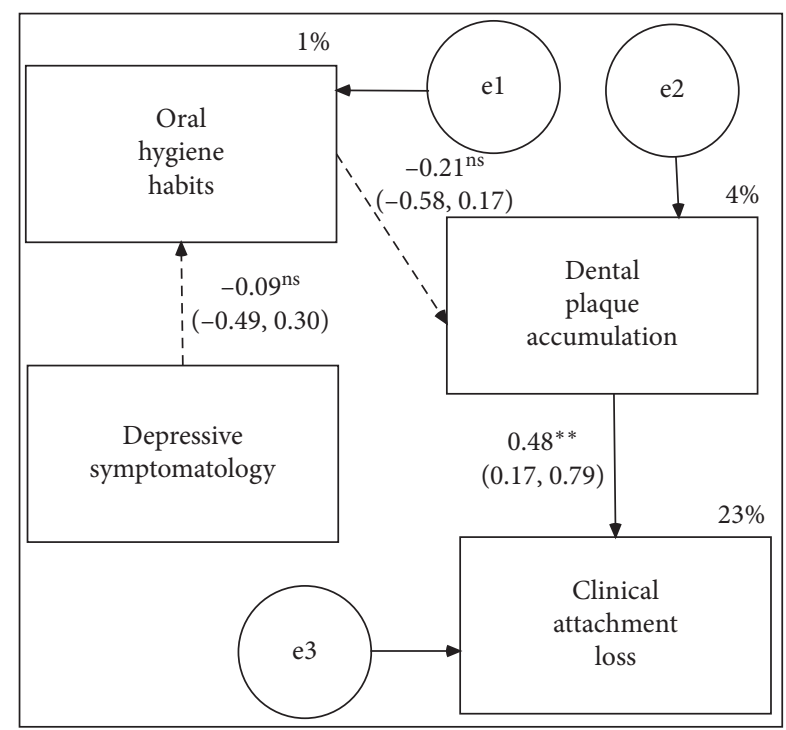

FIGURE 3: Maximum-likelihood parameter point estimates and 95\% Monte Carlo confidence intervals (with 10,000 bootstrap samples) in the mental health sample of 26 patients with depressive symptomatology.

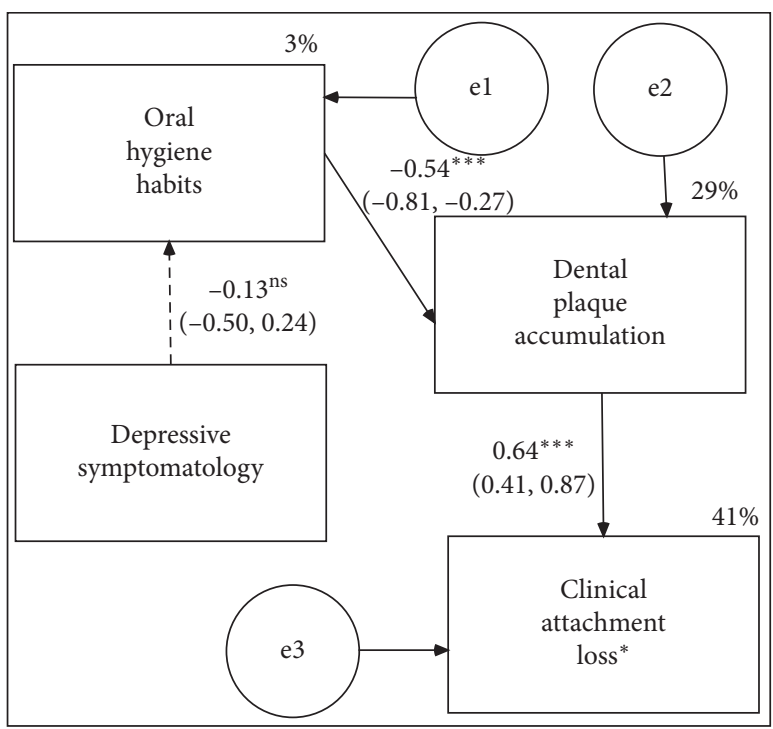

FIGURE 4: Maximum-likelihood parameter point estimates and 95\% Monte Carlo confidence intervals (with 10,000 bootstrap samples) in the general population sample of 29 participants. ${ }^{*}$ The squared clinical attachment loss scores were used, since this mathematical transformation improved their fit to normal distribution.

nonprobabilistic incidental sampling [32]. The null hypothesis of randomness was maintained in the variables including in the model as well as in the items composing 2 psychometric scales. Therefore, the data sequences of the 3 samples can be considered random.

In the design of this cross-sectional study, we tried to achieve an equivalence in sociodemographic characteristics between the 3 samples so that there were no biases due to different sociodemographic composition and were more comparable. First, the 2 clinical samples were collected and then the general population sample, with which we tried to achieve this equivalence. Statistical analysis shows that this objective was met. The 3 samples are equivalent in size and sociodemographic characteristics.

The only difference was in the occupation variable. Office employees dominated and its proportion was statistically equivalent between the 3 samples. However, the sample of dental patients had the highest proportion of blue-collar workers (unskilled manual workers and low-skilled technicians) and the sample of mental health patients had the highest proportion of housewives. What caused the difference in these occupational categories? On the one hand, housewives dominate among middle-aged women who attend depression treatments, which is attributed precisely to their occupational role [33]. On the other hand, the intersection of sex (man) and occupation (blue-collar worker) is a risk factor for periodontitis with a large effect size [34]. Consequently, these differences are determined by the characteristics of each population.

The 3 samples were balanced in terms of sex, which is a representative feature of the general population [35] and patients with periodontitis [19], although the sex ratio among depressive patients is approximately 2 women per 1 man [33]. The 3 samples were also balanced in terms of age. The age range was limited based on the prevalence of periodontitis $[19,20]$. The minimum age was 35 years and the maximum age was 65 . Adults over 65 years of age were not included, since it constituted a subpopulation with respect to periodontal pathology [21]. The average age was equivalent among the 3 groups, dominating middle-aged adults (between 40 and 59 years old). The distribution of the 5 qualitative categories of civil status among the 3 samples was also equivalent. Two-thirds of the participants were married, followed by a tenth of separated or divorced persons, which is representative of the civil status of middleaged adults in Mexico [35]. The median schooling corresponded to high school and the median of the subjective socioeconomic status (SSES) to middle-middle. Both medians were equivalent among the 3 samples and correspond to those of the urban population of Monterrey for schooling and objective socioeconomic status [36]. However, the upper-middle and high SSES were not represented. This was due to the fact that patient samples were collected in clinics belonging to a public university [37]. It should be noted that objective and subjective measurements of the socioeconomic status have high correlations [38]. Since it is easier to determine the SSES, especially given the sensitivity of providing the information necessary to estimate the objective socioeconomic status, and being a better predictor of health outcomes [39], it was decided to measure SSES.

In the study design, an equivalence in sociodemographic variables was intended to avoid biases and reinforce the effects attributable to the variables included in the model. However, it was an expected difference among the samples in the variables including in the model. According to the expectative for the design [13], the CAL and plaque index means in dental patients were significantly higher than the 
corresponding means in general population and mental health patients, and there were no mean differences between the latter 2 groups. It should be noted that there were only cases without CAL in the general population, approximately a fifth. The periodontal health was rather bad in the 3 samples from the indicator of the CAL. This result contrasts with the lower prevalence of periodontitis reported by the Health Secretary in the general population [19], but it does coincide with other research studies on CAL carried out in the general population from Latin American countries, such as Chile, Colombia and Guatemala [40], and Mexico [41].

Regarding psychosocial variables, the mean of depressive symptomatology in the mental health patient sample was greater than the means in the dental patient and general population samples, between which there was no difference. In the samples of the general population and dental patients, there were no cases of depression; when the mean of depressive sintomatology in the mental health patient sample corresponded to a moderate level $[14,15,18]$. These data fit the expected difference $[14,15]$. On the other hand, using an omnibus test (Fisher's ANOVA) with a significance level set at 0.01 , there was a significant difference in means of oral hygiene habits among the 3 samples, and using Fisher's least significant difference test, there was a significant difference between the means of dental patient and general population samples in a 2-tailed test with a significance level set at 0.05 . These data also fit the expected difference. Clearly, regular oral hygiene habits prevail. Good oral hygiene habits were only found in approximately a fifth of the general population sample and a twentieth of the 2 samples of patients. This low proportion of good habits is also observed in other studies $[40,41]$.

The objective enunciated for this study was to test a model to predict the CAL by direct effect of the dental plaque accumulation and indirect effect of poor oral hygiene habits (mediated by dental plaque accumulation) and depressive symptomatology (mediated by oral hygiene habits and dental plaque accumulation) [42]. To this end, path analysis was used, since this technique does not require a large sample [29]. Despite the limited sample size, there were approximately 5 participants per parameter to estimate, which is usually considered an adequate minimum [43]. Since no measurement models were included, the internal consistency reliability of each scale was checked and reliability levels varied from good (in dental patients) to excellent (in general population). In addition, the ordinal omega coefficient was used to estimate the reliability instead of the Cronbach alpha coefficient, since it is the most suitable for ordinal variables, such as Likert-type items, and does not require equivalence of variances and covariances between the items [25]. The assumption of normality was also tested. Data showed a good approximation to multivariate normality, and this opened up the possibility of an analysis strategy to compensate for the limited sample size, such as the use of parametric bootstrap [30]. The standard error of each parameter was estimated by this method and this bootstrap error was used to test the significance of the parameter. To this end, a very large number of random samples, namely, 10,000 bootstrap samples, were generated.
Precisely, this procedure is considered one of the most appropriate practices for data analysis, but it is usually ignored [31]. The implementation of these procedures, the positive results of reliability, and the fulfillment of assumptions made it possible to adapt the data analysis to the research objective.

Three hypotheses were formulated to specify the predictive model. The first hypothesis about the direct effect of depressive symptomatology on oral hygiene habits and its indirect effect on dental plaque mediated by oral hygiene habits was not confirmed. The structural weights were not significant in any of the 3 samples, even if the 3 samples are pooled. These results contrast with the study conducted in Italy by Luca, Luca, Vittorio, Grasso, and Calandra [11], where the researchers state that the severity of depression results in worse periodontal health, greater dental plaque accumulation, and poorer oral hygiene habits. Other studies have also found that depression increases the risk of periodontal disease $[6,7]$ and negligence in oral hygiene [9]. However, the strength of association is small and the present data coincide with studies in which the association of periodontitis and depression has not been significant $[44,45]$, including a meta-analysis [10].

The second hypothesis to specify the model stated that oral hygiene habits have a direct effect on dental plaque and an indirect effect on CAL mediated by dental plaque. The evidence in favor of this hypothesis was provided by the general population sample and pooled sample. In the 2 samples of patients, the weights were not significant, but their signs corresponded to the hypotheses. Therefore, the present results support the assertion that oral hygiene instructions are important to preserve periodontal health and minimize disease activity in the general population $[7,46]$. It should be noted that smoking [47], diabetes [48], pregnancy [49], and wearing orthodontic appliances [50] are factors that increase the risk of periodontitis, but in the present study they were controlled through elimination, that is, there were no cases in the samples. Therefore, poor oral hygiene is directly attributable to deficient brushing technique and not using or misusing dental floss without any interaction of any of these 4 factors.

Finally, the third hypothesis to specify the model stated that the dental plaque accumulation has a direct effect on CAL. This hypothesis was confirmed in all samples. The size of the effect of dental plaque on CAL was large in the general population sample and pooled sample and was medium in the 2 patient samples. Dental plaque is the primary etiological factor of periodontal disease in patients with depression [51] and in patients without depression [52]. Its accumulation causes inflammation and CAL [6, 12, 42]. Therefore, these data are consistent with the positioning of the American Academy of Periodontics, which states that periodontitis is associated with the presence of dental plaque, CAL, and bone loss [2].

A first limitation of the study is the use of nonprobabilistic sampling, and thus, inferences should be taken with due caution in dental patients with periodontitis, mental health patients with depressive symptoms, and general population persons resident in Monterrey and its 
metropolitan area, all of them were middle-aged adults corresponding to a SSES varying from low to middle-middle. All the patients were attended in public or university clinics (focused on low-income people), so people of medium-high or high ESES and professionals were absent in the 3 samples. A second limitation is the reduced sample size. This implies that weak or trivial associations at the population level may be nonsignificant in the sample. Despite the efforts made in the data analysis to overcome the limitations (verification of assumptions of randomness and multivariate normality, and the use of repetitive sampling procedures with a high number of bootstrap samples to generate errors in the estimates), this research should be considered as a pilot study as a result of a second limitation. A third limitation is the nonexperimental cross-sectional design; therefore, no causal inferences can be made and only predictive relationships are discussed.

\section{Conclusion}

The hypothetical predictive model is partially validated. The direct effect of the dental plaque index on CAL is confirmed in the 3 samples with a medium effect size in dental patients with periodontitis and mental health patients with depressive symptomatology and large effect size in general population. Both the direct effect of oral hygiene habits on the dental plaque accumulation and its indirect on the CAL mediated by dental plaque accumulation are confirmed, although only in the sample of general population. Nevertheless, depressive symptomatology is an irrelevant variable, since its direct effect on oral hygiene habits and indirect effect on dental plaque or CAL were not significant in any sample; moreover, the modification indexes for the fit improvement did not suggest any additional path for this variable.

It is suggested to focus on public health interventions on oral hygiene habits to reduce dental plaque and prevent periodontitis, especially in general population. It is invited to promote dental consultation assistance in symptomatic patients to achieve better oral health. It seems that the study of the effect of oral hygiene habits on periodontitis is more fruitful in the general population than in very specific clinical populations. This article joins the set of studies that conclude that depressive symptoms do not have a relevant role in the etiology of periodontitis [10]. Although it could be considered as a pilot study because its sample size was limited (approximately 30 cases per sample and 90 in the pooled sample) and it has a cross-sectional design, trivial or very small effect sizes of depression on oral hygiene habits, dental plaque accumulation, and CAL are replicable results with a larger sample size ( $\geq 200$ per sample and 600 in the pooled sample) due to the analysis methodology used (path analysis, estimation in each sample and in the pooled sample, and bootstrapping). Consequently, the variable depression is not important for preventive purposes. Its relevance for treatment requires specific longitudinal data in this regard (pain sensitivity, poor treatment adherence, enhanced side effects, and decreased immune competence) [53]. These effects have been little studied in dental patients treated for periodontitis, and thus, we suggest their study.

\section{Data Availability}

The data files are available upon request from the corresponding author.

\section{Ethical Approval}

The research was approved by the Research Ethics Committee of the Psychiatric Rehabilitation Unit (registration key CONBIOÉTICA 19CEI01720130828). The research was registered in the Department of Education, Health Research and Quality of the Health Services of Nuevo León with registration number DEISC-19-01-16-16. People who were detected periodontitis were offered treatment in the Periodontics Clinic of the UANL Faculty of Dentistry.

\section{Consent}

Informed written consent was requested and the information was kept strictly confidential in accordance with the Regulations of the General Health Law on Research Subject for Health [54] and 1964 Helsinki Declaration and its later amendments [55].

\section{Conflicts of Interest}

The authors declare that they have no conflicts of interest.

\section{Acknowledgments}

The authors express their acknowledgements for the support received to collect the sample of mental health patients to Dr. Severiano Lozano González, Director of the Psychiatric Rehabilitation Unit, and Dr. Perla Elizabeth Orozco González, Research Coordinator, Department of Teaching, Training, and Research, Secretary of Health of the State of Nuevo León; to Dr. Stefan Mauricio Fernández Zambrano, Head of the Department of Psychiatry, UANL University Hospital; and to Dr. Guillermo Vanegas Arrambide, Deputy Director of Educational and Assistance Projects and M.Sc. Miguel Villegas Lozano, Coordinator of the Department of Equity and Gender, Psychological Services Unit, UANL Faculty of Psychology. The research was funded by Consejo Nacional de Ciencia y Tecnología (CONACyT), grant number scholarship (\#335643).

\section{References}

[1] American Academy of Periodontology, Glossary of Periodontal Terms, American Academy of Periodontology, Chicago, IL, USA, 2019, https://members.perio.org/libraries/glossary? _ga $=2.220572443 .2048029669 .1566420619-1922760749$. $1510809338 \&$ ssopc $=1$.

[2] P. N. Papapanou, M. Sanz, N. Buduneli et al., "Periodontitis: consensus report of workgroup 2 of the 2017 world workshop on the classification of periodontal and peri-implant diseases and conditions," Journal of Periodontology, vol. 45, no. 20, pp. 162-170, 2018.

[3] B. Holtfreter, J. M. Albandar, T. Dietrich et al., "Standards for reporting chronic periodontitis prevalence and severity in 
epidemiologic studies," Journal of Clinical Periodontology, vol. 42, no. 5, pp. 407-412, 2015.

[4] J. Caton, G. Armitage, T. Berglundh et al., "A new classification scheme for periodontal and periimplant diseases and conditions. Introduction and key changes from the 1999 classification," Journal of Clinical Periodontology, vol. 45, no. 20, pp. 1-8, 2018.

[5] J. M. Albandar, C. Susin, and F. J. Hughes, "Manifestations of systemic diseases and conditions that affect the periodontal attachment apparatus: case definitions and diagnostic considerations," Journal of Periodontology, vol. 45, no. 20, pp. 171-189, 2018.

[6] A. Lertpimonchai, S. Rattanasiri, S. Arj-Ong Vallibhakara, J. Attia, and A. Thakkinstian, "The association between oral hygiene and periodontitis: a systematic review and metaanalysis," International Dental Journal, vol. 67, no. 6, pp. 332-343, 2017.

[7] D. Slot, L. Wiggelinkhuizen, N. Rosema, and G. Van der Weijden, "The efficacy of manual toothbrushes following a brushing exercise: a systematic review," International Journal of Dental Hygiene, vol. 10, no. 3, pp. 187-197, 2012.

[8] C. A. Okoro, T. W. Strine, P. I. Eke, S. S. Dhingra, and L. S. Balluz, "The association between depression and anxiety and use of oral health services and tooth loss," Community Dentistry and Oral Epidemiology, vol. 40, no. 2, pp. 134-144, 2012.

[9] A. E. Rosania, K. G. Low, C. M. McCormick, and D. A. Rosania, "Stress, depression, cortisol, and periodontal disease," Journal of Periodontology, vol. 80, no. 2, pp. 260-266, 2009.

[10] M. M. Araújo, C. C. Martins, L. C. M. Costa et al., "Association between depression and periodontitis: a systematic review and meta-analysis," Journal of Clinical Periodontology, vol. 43, no. 3, pp. 216-228, 2016.

[11] M. Luca, A. Luca, C. M. A. Vittorio Grasso, and C. Calandra, "Nothing to smile about," Neuropsychiatric Disease and Treatment, vol. 10, no. 275, pp. 1999-2008, 2014.

[12] J. Slots, "Periodontitis: facts, fallacies and the future," Periodontology 2000, vol. 75, no. 1, pp. 7-23, 2017.

[13] P. N. Papapanou and C. Susin, "Periodontitis epidemiology: is periodontitis under-recognized, over-diagnosed, or both?," Periodontology 2000, vol. 75, no. 1, pp. 45-51, 2017.

[14] A. T. Beck, R. A. Steer, and G. K. Brown, Manual for the Beck Depression Inventory-II, Psychological Corporation, San Antonio, USA, 1996.

[15] A. T. Beck, R. A. Steer, and G. K. Brown, BDI-II. Inventario de Depresión de Beck-II (Spanish adaptation by Jesús Sanz and Carmelo Vázquez), Pearson Educación, Madrid, Spain, 2011.

[16] P. Melo, S. Marques, and O. M. Silva, "Portuguese self-reported oral-hygiene habits and oral status," International Dental Journal, vol. 67, no. 3, pp. 139-147, 2017.

[17] R. Hernández-Sampieri, C. Fernández-Collado, and P. Baptista-Lucio, Metodología de la Investigación, McGrawHill, Ciudad de México, México City, Mexico, 6th edition, 2014.

[18] D. A. González, A. Reséndiz-Rodríguez, A. Reséndiz, and I. Reyes, "Adaptation of the BDI-II in Mexico," Salud Mental, vol. 38, no. 4, pp. 237-244, 2015.

[19] Secretaría de Salud, Resultados del Sistema de Vigilancia Epidemiológica de Patologías Bucales. SIVEPAB 2017, Secretaría de Salud, Ciudad de México, México City, Mexico, 2017, https:// www.gob.mx/salud/acciones-y-programas/sivepab-sistema-devigilancia-epidemiologica-de-patologias-bucales.
[20] J. E. Frencken, P. Sharma, L. Stenhouse, D. Green, D. Laverty, and T. Dietrich, "Global epidemiology of dental caries and severe periodontitis - a comprehensive review," Journal of Clinical Periodontology, vol. 44, no. 18, pp. 94-105, 2017.

[21] E. M. Chávez, L. M. Wong, P. Subar, and D. A. Young, "Wong dental care for geriatric and special needs populations," Dental Clinics of North America, vol. 62, no. 2, pp. 245-267, 2018.

[22] N. I. Rodríguez Franco, J. Moral de la Rubia, and A. G. Alcázar Pizaña, "Predictive model of clinical attachment loss and oral health-related quality of life through depressive symptomatology, oral hygiene habits, and proinflammatory biomarkers: a pilot study," Dentistry Journal, vol. 8, no. 2, pp. 1-21, 2018.

[23] J. Moral and N. I. Rodríguez, "Estructura factorial y consistencia interna de la Escala de Hábitos de Higiene Bucal en muestras de población general y clínica odontológica," Ciencia UAT, vol. 12, no. 1, pp. 36-51, 2017.

[24] S. Turesky, N. D. Gilmore, and I. Glickman, "Reduced plaque formation by the chloromethyl analogue of victamine C," Journal of Periodontology, vol. 41, no. 1, pp. 41-43, 1970.

[25] C. Viladrich, A. Angulo-Brunet, and E. Doval, "Un viaje alrededor de alfa y omega para estimar la fiabilidad de consistencia interna," Anales de Psicología, vol. 33, no. 3, pp. 755-782, 2017.

[26] H. F. Özdemir, Ç. Toraman, and Ö. Kutlu, "The use of polychoric and Pearson correlation matrices in the determination of construct validity of Likert type scales," Turkish Journal of Education, vol. 8, no. 3, pp. 180-195, 2019.

[27] M. T. Barendse, F. J. Oort, and M. E. Timmerman, "Using exploratory factor analysis to determine the dimensionality of discrete responses," Structural Equation Modeling: A Multidisciplinary Journal, vol. 22, no. 1, pp. 87-101, 2015.

[28] F. Timmerman, Scale Development: Theory and Applications, SAGE Publications, Los Angeles, CA, USA, 4th edition, 2016.

[29] B. Byrne, Structural Equation Modelling with AMOS: Basic Concepts, Applications, and Programming, Routledge, New York, NY, USA, 3rd edition, 2016.

[30] K. J. Preacher and J. P. Selig, "Advantages of Monte Carlo confidence intervals for indirect effects," Communication Methods and Measures, vol. 6, no. 2, pp. 77-98, 2012.

[31] A. M. Schoemann, A. J. Boulton, and S. D. Short, "Determining power and sample size for simple and complex mediation models," Social Psychological and Personality Science, vol. 8, no. 4, pp. 379-386, 2017.

[32] M. A. Bujang, F. E. Sapri, and F. E. Sapri, "An Application of the runs test to test for randomness of observations obtained from a clinical survey in an ordered population," Malaysian Journal of Medical Sciences, vol. 25, no. 4, pp. 146-151, 2018.

[33] C. Kuehner, "Why is depression more common among women than among men?" The Lancet Psychiatry, vol. 4, no. 2, pp. 146-158, 2017.

[34] M. Carasol, J. C. Llodra, A. Fernández-Meseguer et al., "Periodontal conditions among employed adults in Spain," Journal of Clinical Periodontology, vol. 43, no. 7, pp. 548-556, 2016.

[35] Consejo Nacional de Población, La situación demográfica de México 2018, Secretaría de Gobernación y CONAPO, Ciudad de México, Consejo Nacional de Población, México City, Mexico, 2019, https://www.gob.mx/conapo/documentos/lasituacion-demografica-de-mexico-2018.

[36] V. M. Maldonado and G. Alarcón, "Cambio demográfico en Nuevo León. Realidad, datos y espacio," Revista Internacional de Estadística y Geografía, vol. 7, no. 3, pp. 4-23, 2016. 
[37] J. C. Maya, N. Sánchez, A. Posada, A. A. Agudelo, and J. E. Botero, "Condición periodontal y su relación con variables sociodemográficas y clínicas en pacientes adultos de una institución docencia-servicio," Revista Odontológica Mexicana, vol. 21, no. 3, pp. 165-172, 2017.

[38] T. Doshi, B. L. Smalls, J. S. Williams, T. E. Wolfman, and L. E. Egede, "Socioeconomic status and cardiovascular risk control in adults with diabetes," The American Journal of the Medical Sciences, vol. 352, no. 1, pp. 36-44, 2016.

[39] E. Zang and A. R. Bardo, "Objective and subjective socioeconomic status, their discrepancy, and health: evidence from East Asia," Social Indicators Research, vol. 143, no. 3, pp. 765-794, 2019.

[40] A. Duque, "Prevalencia de periodontitis crónica en Iberoamérica," Revista Clínica de Periodoncia, Implantología y Rehabilitación Oral, vol. 9, no. 2, pp. 208-215, 2016.

[41] A. Zerón, "Editorial," Revista de la Asociación Dental Mexicana, vol. 74, no. 2, p. 62, 2017.

[42] P. Bouchard, M. C. Carra, A. Boillot, F. Mora, and H. Rangé, "Risk factors in periodontology: a conceptual framework," Journal of Clinical Periodontology, vol. 44, no. 1, pp. 125-131, 2017.

[43] D. L. Jackson, "Sample size and number of parameter estimates in maximum likelihood confirmatory factor Analysis: a Monte Carlo investigation," Structural Equation Modeling: A Multidisciplinary Journal, vol. 8, no. 2, pp. 205-223, 2001.

[44] G. R. Persson, R. E. Persson, C. I. MacEntee, C. C. I. I. Wyatt, L. G. Hollender, and H. A. Kiyak, "Periodontitis and perceived risk for periodontitis in elders with evidence of depression," Journal of Clinical Periodontology, vol. 30, no. 8, pp. 691-696, 2003.

[45] A. C. O. Solis, A. H. Marques, C. M. Pannuti, R. F. M. Lotufo, and F. Lotufo-Neto, "Evaluation of periodontitis in hospital outpatients with major depressive disorder," Journal of Periodontal Research, vol. 49, no. 1, pp. 77-84, 2014.

[46] A. Wolff and H. Staehle, "Improving the mechanical properties of multiuse dental floss holders," International Journal of Dental Hygiene, vol. 12, no. 4, pp. 245-250, 2014.

[47] F. R. M. Leite, G. G. Nascimento, F. Scheutz, and R. López, "Effect of smoking on periodontitis: a systematic review and meta-regression," American Journal of Preventive Medicine, vol. 54, no. 6, pp. 831-841, 2018.

[48] Y. S. Khader, A. S. Dauod, S. S. El-Qaderi, A. Alkafajei, and W. Q. Batayha, "Periodontal status of diabetics compared with nondiabetics: a meta-analysis," Journal of Diabetes and Its Complications, vol. 20, no. 1, pp. 59-68, 2006.

[49] R. P. Esteves Lima, R. M. Cyrino, B. de Carvalho Dutra et al., "Association between periodontitis and gestational diabetes mellitus: systematic review and meta-analysis," Journal of Periodontology, vol. 87, no. 1, pp. 48-57, 2016.

[50] S. N. Papageorgiou, A. A. Papadelli, and T. Eliades, "Effect of orthodontic treatment on periodontal clinical attachment: a systematic review and meta-analysis," European Journal of Orthodontics, vol. 40, no. 2, pp. 176-194, 2018.

[51] S. Shrestha, S. Sharma, N. Sapkota, D. K. Giri, and D. Baral, "Association between anxiety and depression with chronic periodontitis," Journal of College of Medical Sciences-Nepal, vol. 13, no. 2, pp. 268-274, 2017.

[52] D. Kinane, P. G. Stathopoulou, and P. N. Papapanou, "Periodontal diseases," Nature Reviews Disease Primers, vol. 22, no. 3, Article ID 17038, 2017.

[53] B. Laurence and D. Woods, "Depression and dental outcomes," British Dent Journal, vol. 221, no. 3, p. 101, 2016.
[54] Secretaría de Salud, Decreto por el que se reforman, adicionan y derogan diversas disposiciones del Reglamento de la Ley General de Salud en Materia de Investigación para la Salud, Diario Oficial de la Federación, vol. 1-6, Secretaría de Salud, Mexico City, Mexico, 2014http://www.dof.gob.mx/nota detalle.php? codigo $=5339162 \&$ fecha $=02 / 04 / 2014$

[55] General Assembly of the World Medical Association, "World Medical Association Declaration of Helsinki: ethical principles for medical research involving human subjects," Journal of the American College of Dentists, vol. 81, no. 3, pp. 14-18, 2014. 